\title{
Youngest occurrences of rhomaleosaurid plesiosaurs indicate survival of an archaic marine reptile clade at high palaeolatitudes
}

\author{
Roger B.J. Benson, Nikolay G. Zverkov, and Maxim S. Arkhangelsky \\ Acta Palaeontologica Polonica 60 (4), 2015: 769-780 doi:http://dx.doi.org/10.4202/app.00167.2015
}

Rhomaleosaurid plesiosaurians were a common and ecologically significant component of Early Jurassic marine faunas, primarily as large-bodied predators. They declined in abundance and made their last fossil appearance in the Middle Jurassic. However, the geographic pattern of rhomaleosaurid extinction has thus far been obscured by spatial bias in the Middle Jurassic marine reptile fossil record, which is strongly focussed on low-latitude European assemblages. We report two rhomaleosaurid specimens from the Callovian (late Middle Jurassic) of the UK and Russia. Along with Borealonectes from Arctic Canada, these are the youngest-known occurrences of rhomaleosaurids. The UK specimen is the first identified from the Callovian of Europe, despite intensive fossil sampling over almost 200 years and the recovery of hundreds of other plesiosaurian specimens. Its discovery indicates that rhomaleosaurids were present, but extremely rare, at low palaeolatitudes of the Callovian.

The Russian specimen is one of relatively few marine reptile specimens from its mid-palaeolatitude assemblage, as is also true of Borealonectes, which occurs in a high-palaeolatitude marine assemblage. Furthermore, we suggest that a mid latitude southern hemisphere occurrence from the Callovian of Argentina, previously referred to Pliosauridae, in fact represents a rhomaleosaurid. These findings suggest that rhomaleosaurids were actually common elements of mid-high palaeolatitude marine faunas, indicating a geographically staggered pattern of declining rhomaleosaurid abundance, and demonstrating the apparent persistence of an archaic marine reptile group in cool, mid-high latitude environments of the Middle Jurassic. It is therefore possible that sustained Middle-Late Jurassic global warming accelerated the ultimate extinction of rhomaleosaurids. Our findings suggest that widening the geographical breadth of fossil exploration could considerably enhance current knowledge of Jurassic marine reptile evolution.

Key words: Plesiosauria, Rhomaleosauridae, biogeography, Jurassic, Callovian, UK, Russia.

Roger B.J. Benson [roger.benson@earth.ox.ac.uk] Department of Earth Sciences, University of Oxford, South Parks Road, Oxford OX1 3AN, United Kingdom. Nikolay G. Zverkov [zverkovnik@rambler.ru] Lomonosov Moscow State University, 1 Leninskie Gory, Moscow 119991, Russia. Maxim S. 
Arkhangelsky [paleozoo@gmail.com] Saratov State Technical University, 77 Politekhnicheskaya Street, Saratov 410054, Russia; Saratov State University, 83 Astrakhanskaya Street, Saratov 410012, Russia.

This is an open-access article distributed under the terms of the Creative Commons

Attribution License (for details please see creativecommons.org), which permits unrestricted use, distribution, and reproduction in any medium, provided the original author and source are credited.

Forif Full text $(1,138.0 \mathrm{kB})$ 